\title{
Margens capitais: o desenho e o canteiro da manufatura
}

Capital limits: the design and the manufacturing workplace

Humberto Pio Guimarães*

*Professor na pós-graduação em Design de interiores contemporâneo no Instituto Europeu de Design em São Paulo. Mestre pela Universidade de São Paulo em 2006 com dissertação sobre Rodrigo Lefèvre. Poeta autor de Coágulo (Editora Reformatório, 2019).

\section{Palavras-chave:}

Arquitetura.

Canteiro de obras.

Sérgio Ferro.

\section{Keywords:}

Architecture.

Construction Site

Sérgio Ferro.
Resumo $\quad$ Abstract

Flávio Império e Rodrigo Lève com coorente paulista da arquito de moderna no âmbito da ideologia e da linguagem, anterior ao golpe militar de 1964 e à crítica radical que elaborariam na sequência, filiada à corrente interpretativa de intelectuais brasileiros marxistas, nos termos da dualidade entre arcaico e moderno. Ilumina o comprometimento de suas ideias com usuários e produtores da arquitetura, com vistas a uma solução para a construção de habitações de interesse social. Trata de duas ção para a construção de habitações de interesse social. Trata de duas
residências burguesas projetadas por Ferro, cujos canteiros de obras residências burguesas projetadas por Ferro, cujos canteiros de obras
serviram como laboratórios de manufatura heterogênea - casa Boris Fausto, em São Paulo - e manufatura orgânica - casa Bernardo Isller, em Cotia - essa última em abóboda.

\section{usjt}

\section{arq.urb}

número 29 / set - dez de 2020

Recebido: $10 / 04 / 2020$ Aceito: $19 / 06 / 2020$

approaches the relation in Sérgio Ferro's first production side by side with Flávio Império and Rodrigo Lefèvre and with the São Paulo modern architecture scene in terms of its ideology and language scope before the 1964 military coup and the radical criticism that they would later elaborate. Witch it affiliated to the Brazilian Marxist intellectual interpretive approach, which was related to the duality between archaic and modern. It enlightens the commitment of their ideas to users and architects with a view for a solution for the housing construction with social concern. It is about bourgeois residences designed by Ferro, characterized by construction sites served as heterogeneous manufacturing laboratories - Boris Fausto's house, in São Paulo - and organic manufacture - Bernardo Isller's house, in Cotia - this one in a dome design. 


\section{Margens capitais}

Trabalhando desde quando estudantes em trio, duo ou solo, Flávio Império, Rodrigo Lefèvre e Sérgio Ferro foram autores, na década de 1960, de projetos convergentes, permeados pela preocupação com o sentido da arquitetura, a organização do trabalho no canteiro de obras e a racionalização de sistemas construtivos. Imersos em multidisciplinaridade de atuações como ensino, pintura, crítica e teatro, além da arquitetura, é patente o processo de criação coletiva que os envolvia, conforme relatou-me Sérgio Ferro em entrevista (1995): "havia uma osmose quase que absoluta e nenhuma ciumeira entre nós" - e a proibição do apelo ao sensível - "tínhamos que argumentar, convencer o outro, ou não fazíamos. Não havia o violino, ou quando havia era de propósito e aí era difícil ser coletivo: um propunha e os outros adotavam na hora".

Considero os quatro primeiros anos dessa parceria (1961-4) como o período de gestação de um ideário arquitetônico comum a partir das experiências construtivas de obras projetadas num ateliê coletivo. Assim, as referências da produção são cruzadas e o amálgama cultural resultante sobrevive ao período abordado. Mais do que encontrar respostas definitivas, o trio levantou questões próprias à arquitetura brasileira, tomando seus projetos e obras como laboratório de possibilidades técnicas e espaciais, cujo pano de fundo era o problema da casa popular. Em julho de 1965, esta produção seria pela primeira vez reunida num número especial da revista Acrópole (n. 319).

O editorial de Eduardo Corona "Acerca da habitação popular", deixava claro o mote, seguido de um texto de Vilanova Artigas, cujo recado o título também manifesta: "Uma falsa crise". Se para os três arquitetos o clima naquele momento era de frustração frente à limitação do significado social da arquitetura "num tempo de guerra", Artigas pretendia mostrar que o país, apesar do golpe militar, não saíra dos trilhos da modernização; e que não havia crise do funcionalismo em arquitetura, senão uma "superação de fase" nacional, a partir da autocrítica de Oscar Niemeyer, nova síntese entre técnica e arte, concisão e pureza sobrepondo-se à originalidade excessiva anterior. Finalizava citando Paul Langevin: "o pensamento nasce da ação e, num espírito sadio, volta para a ação." Convite do mestre à prática profissional que minimizava o desejo latente da ação política efetiva por parte dos jovens arquitetos, inaugurando acirrado debate.
Na sequência do periódico, textos de apresentação de Flávio Império, Rodrigo Lefèvre e Sérgio Ferro para o caderno de projetos: "Notas sobre arquitetura". Cada qual reclamava a seu modo da precariedade do mercado de trabalho e do consumo burguês da arquitetura, forçando o arquiteto à atuação em campos próximos como pintura e teatro e ao "interesse pelo levantamento e interpretação dos fatos de nossa cultura", crítica direta ao momento político. Cobrindo a produção arquitetônica de quatro anos, os projetos são apresentados em ordem não cronológica e evidentemente não aleatória, construção de um discurso. Assim, após um projeto urbano e outras três residências, temos em forma de epílogo a casa Boris Fausto (1963), índice do impasse da visão desenvolvimentista voltada para o problema da industrialização na construção civil brasileira. E por fim duas experiências em abóbadas, abrindo picadas: "Residência na praia" - casa Simon Fausto (1961), projeto de Flávio Império - seguida por "Residência em Cotia" - casa Bernardo Issler (1963). A novidade não era apenas formal, mas de ordem técnica: a abóbada refletia alguns dos conceitos norteadores da arquitetura de Ferro, Império e Lefèvre: estrutura quase perfeita - funcionando somente à compressão; melhoria das condições de trabalho no canteiro - protegendo o operário de sol e chuva; e economia de material - tijolo a um só tempo vedo e cobertura. Além disso, as adequações do uso à forma levariam a possibilidades de mudança nos espaços tradicionais da casa.

Em "Arquitetura Nova" (1967), Sérgio Ferro discorre sobre o período entre os anos 1940 e 1960, em que havia sintomas de um provável desenvolvimento social que, verdadeiros ou não, serviram para estimular uma "otimista atividade antecipadora", traduzida por uma "arquitetura sóbria e direta", adequada ao nosso subdesenvolvimento. "Brasília marcou o apogeu e a interrupção dessas esperanças: logo freamos nossos tímidos e ilusórios avanços sociais e atendemos ao toque militar de recoIher". A correta interpretação da dúbia sentença parece-me chave de entendimento para a colaboração primeira dos três arquitetos. Uma leitura possível, conforme proposição do crítico literário Roberto Schwarz no invulgar ensaio Cultura e Política, 1964-69. Alguns esquemas. - em que comenta brevemente o artigo de Ferro - é entender que "o processo cultural, que vinha extravasando as fronteiras de classe e o critério mercantil, foi represado em 64". Seguindo seu raciocínio, a exemplo do que ocorrera com o teatro da época, a "arquitetura nova" teria virado "matéria para consumo próprio", já que o golpe militar rompera o contato esboçado entre os artis- 
tas e os explorados para quem o trabalho se orientava. Daí que os arquitetos vivessem o anticlímax da casa burguesa:

Cortada a perspectiva política da arquitetura, restava entretanto a formação intelectual que ela dera aos arquitetos, que iriam torturar o espaço, sobrecarregar de intenções e experimentos as casinhas que os amigos recém-casados, com algum dinheiro, às vezes Ihes encomendavam. Fora de seu contexto adequado, realizando-se em esfera restrita e forma de mercadoria, o racionalismo arquitetônico transforma-se em ostentação de bom-gosto - incompatível com a sua direção pro-

funda - ou em símbolo moralista e inconfortável da revolução que não houve. ${ }^{1}$

Ao considerarmos as especificidades do campo da arquitetura, essa ideia de "projeto interrompido" parece não se sustentar. De fato, o compromisso social da arquitetura moderna brasileira fora sempre muito tênue. Aquele "brutalismo" identificado por Schwarz como "símbolo moralista" já estava em Artigas, conforme salientou Pedro Arantes:

Moral puritana e controle do uso racional da riqueza, cujo fim é o projeto de modernização burguesa. É por isso que, quando Sérgio fala em "estética empenhada", nós poderíamos completar: ela esteve particularmente empenhada em transformar a casa burguesa e educar a elite. Esta a nossa "causa". (2002, p. 48).

E então passamos a outra leitura possível para aquela sentença, a de que a construção de Brasília explicitou as contradições da modernização brasileira, sendo o ápice e a ruptura do comprometimento da arquitetura com o desenvolvimento do país. A curva descendente aqui é anterior à da cultura em geral, nos quatro anos entre a inauguração da cidade e o golpe militar. A concretização do Plano Piloto e seu contraste em relação às cidades satélites evidenciava as limitações das condições da época e iluminava as contradições do projeto político e sua inexequibilidade nos marcos em que vinha sendo proposto. ${ }^{2}$

Realidade bifurcada, Brasília foi a um só tempo a afirmação do desigual e combinado e o símbolo da impossibilidade de superação dessa realidade pela vias pacíficas ou institucionais, que desaguaria na eleição de Jânio Quadros e no populismo radical de João Goulart, ao qual se atrelava a esquerda. A dualidade entre o arcaico

\section{'Op. cit., p. 79}

${ }^{2}$ Paulo Bicca, em ensaio crítico, promove um interessante paralelo entre Brasília e a Torre de Babel para realçar "a irracionalidade de um projeto generoso e a distância entre intenções e resultados".
Margens capitais: o desenho e o canteiro da manufatura

e o moderno não lhe era exógena e a interrupção do processo democrático em 1964 não anulou o processo de modernização e o desenvolvimento econômico que a induziram. Desenvolvimentismo, claro, sem projeto social renovador: ao passo em que cresciam as desigualdades sociais, ampliando-se a concentração de renda, os militares exacerbavam o desenvolvimento técnico-industrial e o ideal nacionalista de progresso. Tendo projetado junto com Lefèvre dois edifícios na nova capital, Ferro em depoimento disse o seguinte:

Militância política e formação profissional vieram quase juntas. Desde o segundo ano de FAU-USP, já tinha obras em execução, particularmente em Brasília. O contraste absurdo entre o discurso profissional dominante, em geral aparentemente generoso e de esquerda, e a realidade assustadora dos canteiros de obra não podia ser desconsiderado a não ser por máfé. Acompanhei de perto o horror dos canteiros de Brasília. Por obrigação ética, fui obrigado a rever as certezas enfunadas da profissão - e assim continuo ainda hoje. (2002b, p. 141).

Corroborando tal afirmação, minha hipótese é a de que a compreensão dos limites do caso assinalado estaria já na raiz dos primeiros projetos conjuntos de Flávio Império, Rodrigo Lefèvre e Sérgio Ferro, a partir de certa consciência dos meios de produção em arquitetura, ainda não formulada como crítica. Mesmo que vinculada ao processo de desenvolvimento nacional, com o qual a classe dos arquitetos estava comprometida, já apresentava acentuada preocupação com a racionalidade do fazer. Segundo Sérgio Ferro, ainda no começo dos anos 1960, ele e Rodrigo Lefèvre começaram a trabalhar numa hipótese do que seria a arquitetura como manufatura:

O Capital distingue dois tipos de manufaturas diferentes: uma chamada serial e outra chamada heterogênea. Na serial você faz quase tudo no canteiro: faz uma camada, e depois faz outra, e depois faz outra, e depois faz outra. E aquilo vai somando, no fim, a casinha está pronta. $E$ na heterogênea você traz peças que são feitas em usinas ou em depósitos, que são trazidas e montadas no canteiro. As duas são manufaturas. A pré-fabricação no canteiro não é indústria. A

Cf. BICCA, P. R. S. (1985). Brasília: mitos e realidades. In: PAVIANI, A.. (Org.). Brasília, ideologia e realidade - Espaço urbano, em questão. São Paulo: Projeto, p.100-33. 
industrialização dos componentes não tem nada a ver com a industrialização do canteiro, são coisas bastante diferentes. Você pode ter produtos os mais sofisticados no canteiro. E esses produtos mais sofisticados de indústria de ponta entrarão na manufatura dominante, na estrutura dominante. (2002a, p. 18-9).

Recorrendo àquela obra para a maior precisão dos termos, as duas formas da manufatura identificadas por Karl Marx são a heterogênea e a orgânica:

A manufatura se apresenta sob duas formas fundamentais. Embora se combinem eventualmente, constituem duas espécies essencialmente diversas e desempenham papéis inteiramente distintos na transformação posterior da manufatura na grande indústria baseada na maquinaria. Esse duplo caráter decorre da natureza do artigo produzido. Ou o artigo se constitui pelo simples ajuntamento mecânico de produtos parciais independentes [manufatura heterogênea] ou deve sua forma acabada a uma sequência de operações e manipulações conexas [manufatura serial].

Nessa perspectiva, Ferro experimentou em seus primeiros projetos residenciais, ambos de 1963, as "duas formas fundamentais da manufatura", como que a aferir o mais pertinente às condições de produção no Brasil: a casa Boris Fausto - cobertura de concreto armado com configuração interna determinada por painéis pré-fabricados - ensaio de manufatura heterogênea; e a casa Bernardo Issler - abóbada circular construída em sistema de laje pré-moldada, com o auxílio de cambotas de madeira - exemplo de manufatura orgânica.

A casa Boris Fausto, construída no bairro do Butantã, em São Paulo, apresenta um espaço absolutamente fluido organizado por quatro pilares centrais solidários a vigas de metro de altura e seis de balanço, que sustentam laje quadrada de cobertura, estrutura em concreto aparente. O programa arquitetônico obedece a critérios de espaços mínimos e as divisões entre os ambientes são dadas por equipamentos funcionais ${ }^{3}$ executados em placas divisórias de fibrocimento, além de grandes portas pivotantes ou pantográficas, tudo disposto livremente a partir de rígida modulação. Assim, a construção pode ser aberta ou fechada quase que por inteiro, garantindo continuidade entre áreas internas e externas - a casa é um fechamento do jardim - e a integração das áreas de uso coletivo e privado. Espaço subordinado a

${ }^{3}$ Expressão emprestada de Ana Paula Koury para designar móveis construídos durante a obra (camas, mesas, bancadas, bancos, armários etc.); dispositivos de circulação, aquecimento e outros (escadas, patamares, lareiras, churrasqueiras etc.); e também alguns ambientes privativos
Margens capitais: o desenho e o canteiro da manufatura

uma pedagogia social em que o convívio desenha o partido projetual, de modo radical, o conceito de Le Corbusier da "máquina de morar" levado ao extremo, em estética industrial: gárgulas e cilindros de concreto com pedregulhos evidenciando o escoamento das chuvas, iluminação dos banheiros em domos elevados à guisa de chaminés, nichos em compensado naval desgarrados da laje principal ventilados por brises, tubulações aparentes.

Proposta como um "ensaio de incorporação dos progressos técnicos" acabou por apontar os impasses da indústria da construção civil brasileira naquele início dos anos 1960:

As principais dificuldades que surgiram no nosso ensaio, não foram as de mãode-obra que se adaptou facilmente às novas técnicas.

Uma série de "defeitos" de fabricação prejudicou o conjunto da proposta, forçando inúmeros expedientes corretivos (as placas não isolam, pela economia de material, o que a teoria faria supor; o mástique que desaparece sob a ação da água, forçando o emprego de mata-juntas que não estavam previstas etc.). (FERRO, 1965, p. 34).

Outra feita, a casa Bernardo Issler, localizada em Cotia (SP), apresenta pela primeira vez a tipologia da grande cobertura em abóbada com vistas à produção de moradias populares, posteriormente aprimorada por Lefèvre em um grupo de casas projetadas nos anos 1970. A fluidez da casa anterior é mantida. Desta vez, os equipamentos funcionais são construídos em alvenaria e os espaços confinados, ainda mais exíguos, apresentam coberturas independentes em laje pré-moldada de vigotas e blocos cerâmicos, a exemplo da abóbada, procurando não tocá-la no ponto de maior inflexão para que não haja prejuízo da apreensão visual total do espaço, garantida também por um desnível interno. O texto de apresentação de Sérgio Ferro da residência na revista Acrópole tinha tom indissimulável:

A melhor técnica, em determinados casos, nem sempre é a mais adequada. Há mesmo situações em que a modernidade construtiva é fator secundário. Enquanto não for possível a industrialização em larga escala, o déficit habitacional exige o aproveitamento de técnicas populares e tradicionais. Sua racionalização, despreocupada com sutilezas formais e requintes de acabamento, associada a uma interpretação correta de nossas necessidades, favorece, não só o surgimento de

(banheiros, cozinhas e dormitórios), tornados praticáveis, objetos inerentes à montagem e configuração espacial das casas projetadas de maneira a otimizar o aproveitamento de espaço dessas construções. 
uma arquitetura sóbria e rude, mas também estimula a atividade criadora viva contemporânea que substitui, muitas vezes com base no improviso, o rebuscado desenho de prancheta. (n. 319, p. 38)

Quase um manifesto, em que subentendia-se uma crítica ao trabalho de Niemeyer, no "rebuscado desenho de prancheta". Explicitavam-se assim, as coordenadas para o trabalho vindouro do trio de arquitetos, que escolheriam deliberadamente a manufatura orgânica, segundo o próprio Marx a forma perfeita desse modo de produção, como paradigma para a construção civil brasileira.

Não menos importante do que as obras é o ideário formulado em conjunto por Sérgio Ferro, Rodrigo Lefèvre e Flávio Império, ao início dos anos 1960, bem expresso no texto "Proposta Inicial para um Debate: possibilidades de atuação", de autoria dos dois primeiros, editado em 1963 pelo Grêmio de Alunos da FAU-USP, da qual eram docentes desde 1962, ano em que se graduaram pela mesma escola. Uma "poética da economia" estava ali delineada:

Assim é que do mínimo útil, do mínimo construtivo e do mínimo didático necessários tiramos, quase, as bases de uma nova estética que poderíamos chamar a "poética da economia", do absolutamente indispensável, da eliminação de todo o supérfluo, da "economia" de meios para formulação da nova linguagem, para nós, inteiramente estabelecida nas bases da nossa realidade histórica.

Da apropriação de materiais convencionais e formas construtivas correntes, surgiria assim uma nova linguagem, na trilha de outras formulações culturais do período, imbricadas entre a ética e a estética. Para além da singrante produção em pintura e cenografia dos três arquitetos, sua plataforma de ação apresenta algum paralelo com a "estética da fome" de Glauber Rocha e toda a produção do Cinema Novo, que via na carência de meios terceiro-mundistas uma forma de expressão crítica ao modelo da indústria cinematográfica internacional - e por extensão ao desenvolvimentismo brasileiro. Mas há que se ter cuidado: a complexidade desse "miserabilismo" em arquitetura é maior do que a de um tijolo na mão e uma ideia na cabeça, dadas as especificidades da construção civil, atividade manufatureira, no contexto da luta de classes de uma sociedade capitalista. O que estava em jogo era um sentido para a técnica diferente daquele sinalizado pela corrente hegemônica da arquitetura nacional que, a despeito de grandes realizações, não fora capaz de alcançar o povo.
Escrito em 1963, ao tempo da construção das casas Boris Fausto e Bernardo Issler e às vésperas do malfadado golpe, momento em que ainda havia "confiança no andamento do processo num sentido progressista", aquele texto questionava já a pertinência do trabalho do arquiteto no sentido da "evolução das bases econômicas da nossa sociedade", ofício impregnado de maneirismos reflexos de uma "situação no conflito":

No exame da história das propostas que escolhemos, as diversas razões por que foram criadas e desenvolvidas nem sempre aparecem coerentes com o que pretendemos. Na escolha que somos forçados a fazer, a determinação de quais as forças que condicionaram nem sempre é possível. As previsões carregam mais tendências pessoais ou da situação do que se baseiam num andamento suposto e, por vezes, pouco informado. A dúvida é constante em qualquer opção: a angústia originada se acentua pelas intenções estranhas e mesmo desconhecidas com que se apresentam os caminhos.

Ao pé em que Rodrigo Lefèvre e Sérgio Ferro colocavam em xeque a premissa moderna da democratização como consequência natural do progresso, eles contraditoriamente, para quem estava prestes a optar pela manufatura orgânica como solução adequada à arquitetura brasileira - a partir de uma crítica contundente às relações de trabalho na arquitetura elaborada posteriormente - propõem uma "poética da economia", suposta nova linguagem, com raízes que deitam, a bem da verdade, na tradição moderna da manufatura heterogênea, encontrada no campo da arquitetura e do desenho industrial desde a Bauhaus de Gropius.

Voltando ainda mais no tempo, arrisco um paradoxo: a exemplo de William Morris (1834-96) e John Ruskin (1819-1900) - inimigos jurados da primeira indústria e defensores do estetismo, que malgrado suas intenções acabaram por franquear a via de acesso à estética industrial a partir do equacionamento entre forma e função que o desenho moderno realizaria - os três arquitetos reforçavam o panorama capitalista a que buscavam se contrapor, na medida em que o que o estudo virava norma, a causa um estilo, dando eco à voz de "maneiristas do espaço". Mais do que críticos da "escola paulista", Flávio Império, Rodrigo Lefèvre e Sérgio Ferro contribuíram para sua conformação. 
ACRÓPOLE. Flávio Império, Rodrigo Lefèvre e Sérgio Ferro, arquitetos. Acrópole. São Paulo, ano 27, n. 319, jul. 1965. Número Especial.

ARANTES, Pedro Fiori. Arquitetura Nova: Sérgio Ferro, Flávio Império e Rodrigo Lefèvre, de Artigas aos mutirões. São Paulo: Editora 34, 2002.

FERRO, Sérgio. Residência em Cotia. Acrópole. São Paulo, ano 27, n. 319, p. 389, jul. 1965.

_. Residência no Butantã. Acrópole. São Paulo, ano 27, n. 319, p. 34-5, jul. 1965. _. Depoimento a Humberto Pio Guimarães e Luana Geiger [19 set. 1995]. In: GUIMARÃES, Humberto Pio. Projeto Flávio Império - Travessia. O Homem/ Humanista/ Brasileiro. Primeiro Relatório (I.C. - FAPESP), Faculdade de Arquitetura e Urbanismo/ Instituto de Estudos Brasileiros, Universidade de São Paulo; Sociedade Cultural Flávio Império, São Paulo 1996, p. 6-12.

. Conversa com Sérgio Ferro. Conversa aberta com alunos da FAU-USP [27 fev. 2002]. São Paulo, LPG FAU-USP, 2002[a].

. Arquitetura e luta de classes. Entrevista a Lelita Oliveira Benoit. Crítica Marxista. São Paulo, n. 15, p. 140-50, out. 2002[b].

. Arquitetura nova. Teoria e Prática. São Paulo, n. 1, p. 3-15, 1967.

FERRO, Sérgio; LEFÈVRE, Rodrigo Brotero. Proposta inicial para um debate: possibilidades de atuação. In: Encontros GFAU 63, São Paulo: GFAU, 1963.

KOURY, Ana Paula. Grupo Arquitetura Nova. Dissertação (Mestrado) - EESCUSP, São Carlos, 1999.

MARX, Karl. O Capital. Crítica da economia política. São Paulo: Civilização Brasileira, 1968, vol. 1, p. 392-3.

SCHWARZ, Roberto. Cultura e Política, 1964-69. Alguns esquemas. In: O pai de família e outros estudos. 2. ed. Rio de Janeiro: Paz e Terra, 1978.
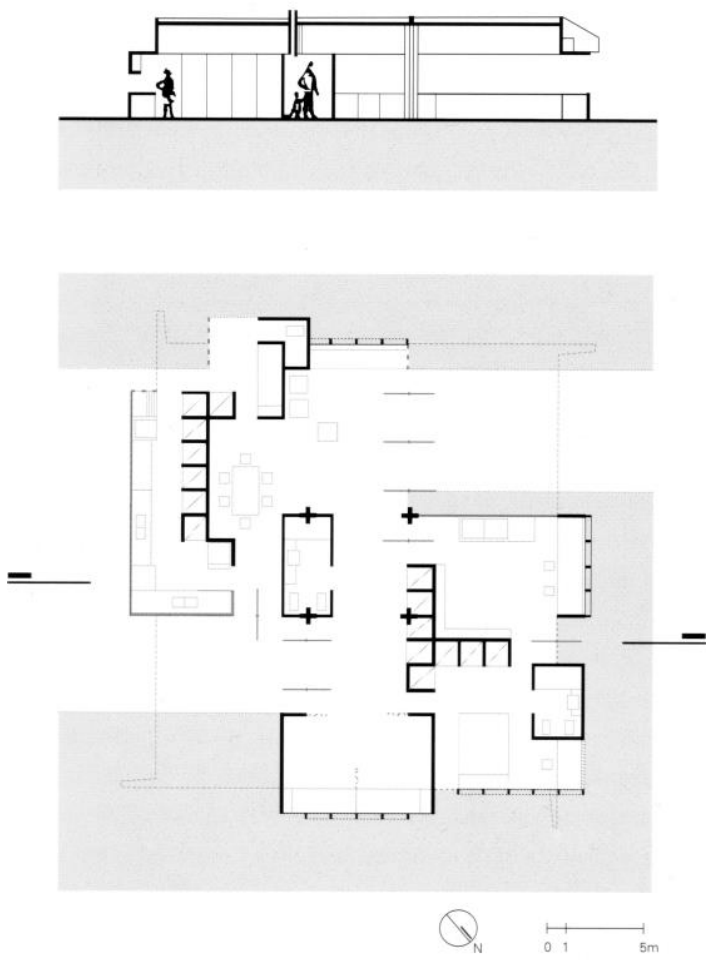

Figura 1. Sérgio Ferro, Casa Boris Fausto. Desenhos (planta e corte) a partir de publicação na revista Acrópole n. 319, jul. 1965. In: KOURY, Ana Paula. Grupo Arquitetura Nova. São Paulo, Romano Guerra, 2003 


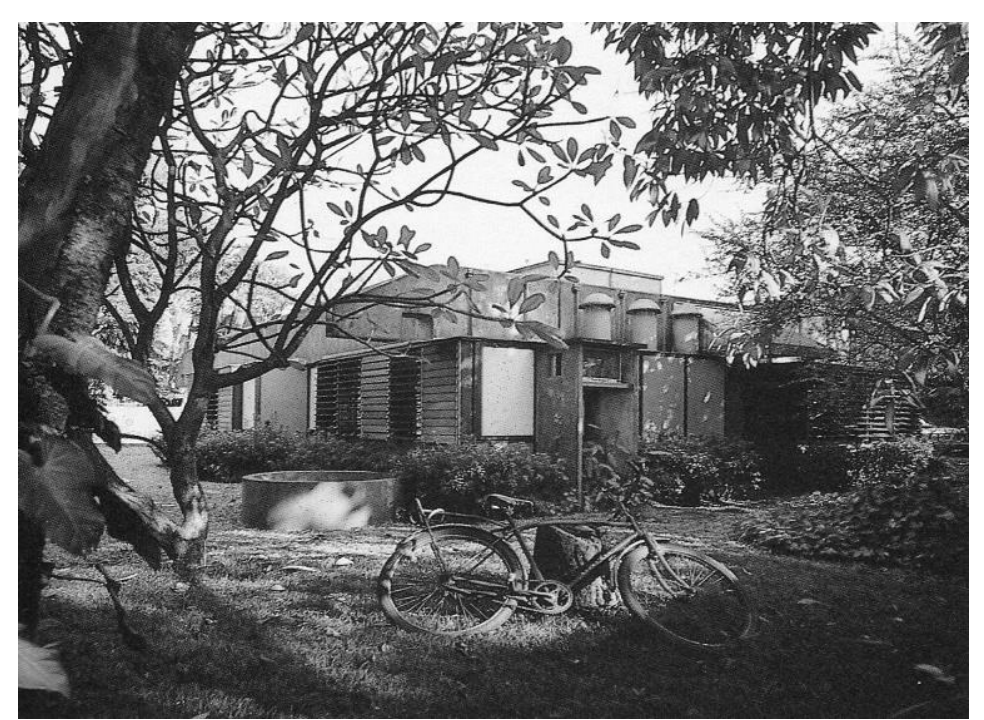

Figura 2. Sérgio Ferro, Casa Boris Fausto. Vista externa. Foto de autoria desconhecida. In: FERRO, Sérgio. Futuro anterior. São Paulo: Nobel, 1989.

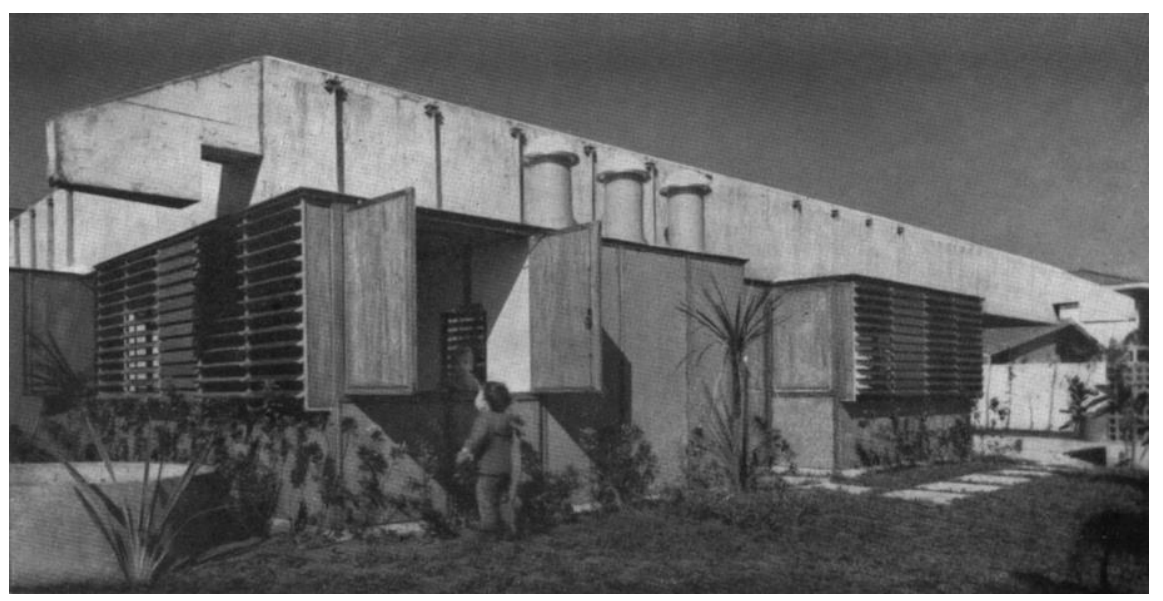

Figura 3. Sérgio Ferro, Casa Boris Fausto. Vista externa. Foto de José Moscardi. In: Acrópole. São Paulo, ano 27, n. 319, jul. 1965

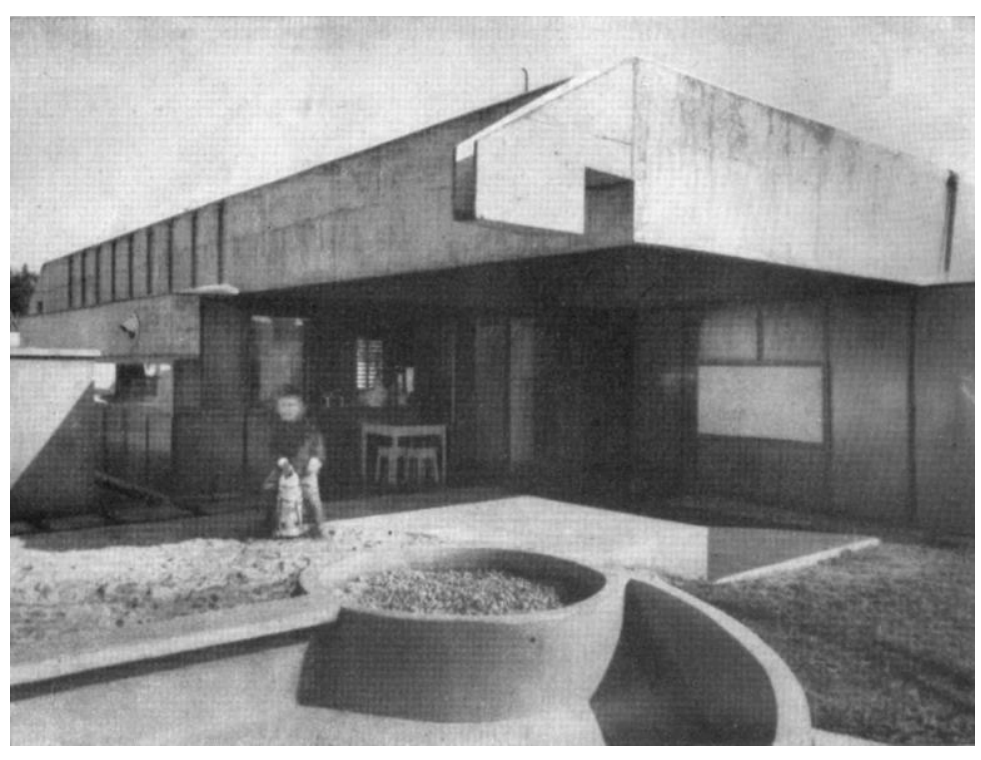

Figura 4. Sérgio Ferro, Casa Boris Fausto. Vista externa. Foto de José Moscardi In: Acrópole. São Paulo, ano 27, n. 319, jul. 1965

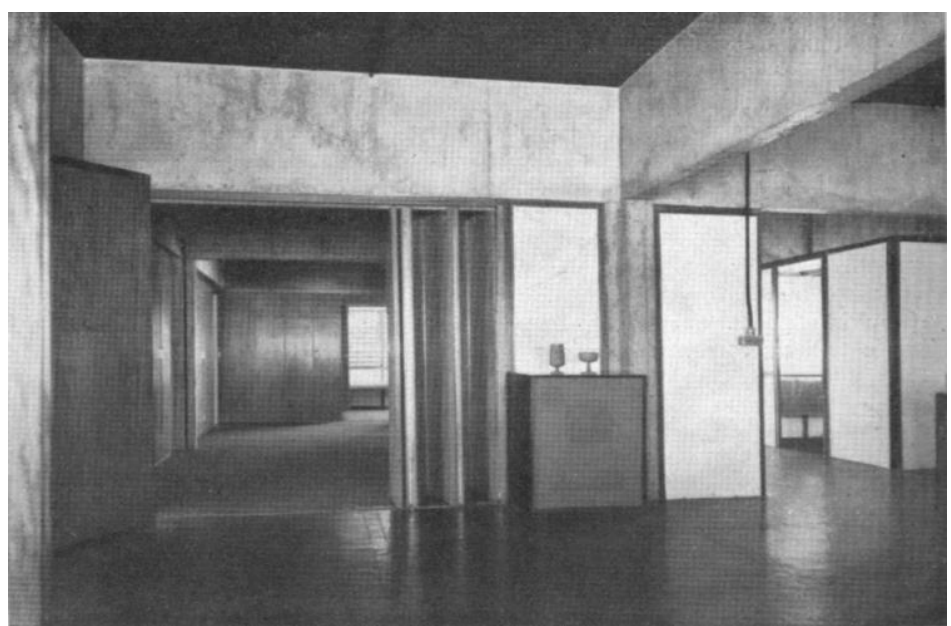

Figura 5. Sérgio Ferro, Casa Boris Fausto. Vista interna. Foto de José Moscardi. In: Acrópole. São Paulo, ano 27, n. 319, jul. 1965 

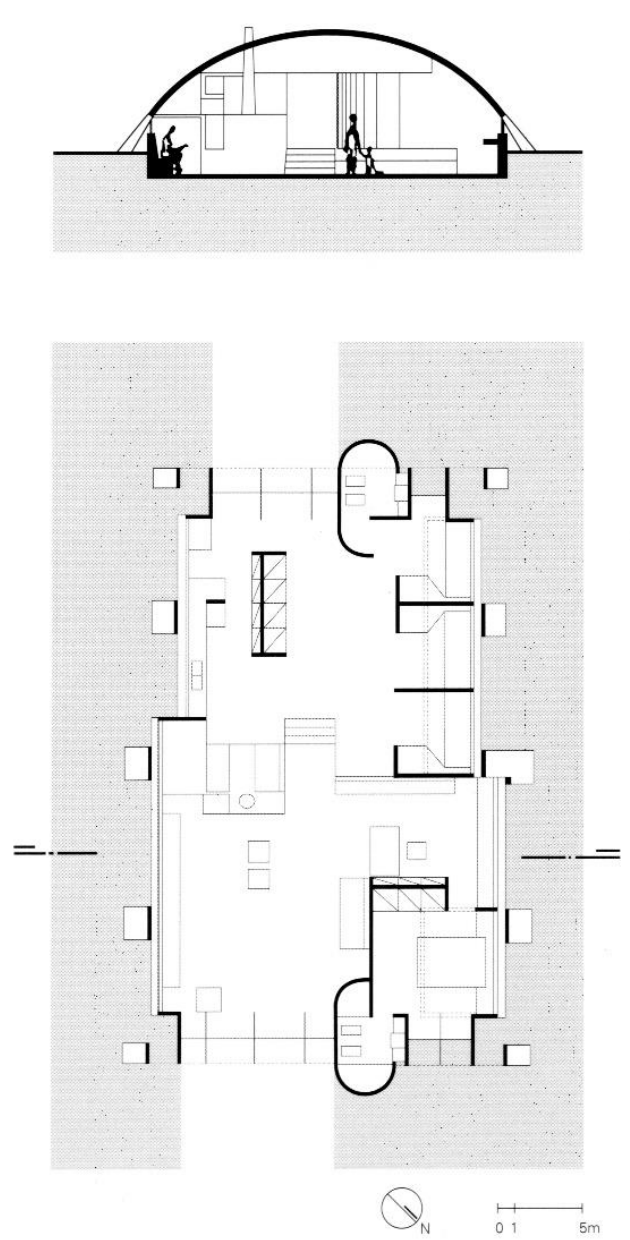

Figura 6. Sérgio Ferro, Casa Bernardo Issler. Desenhos (planta e corte) a partir de publicação na revista Acrópole n. 319, jul. 1965. In: KOURY, Ana Paula. Grupo Arquitetura Nova. São Paulo, Romano Guerra, 2003

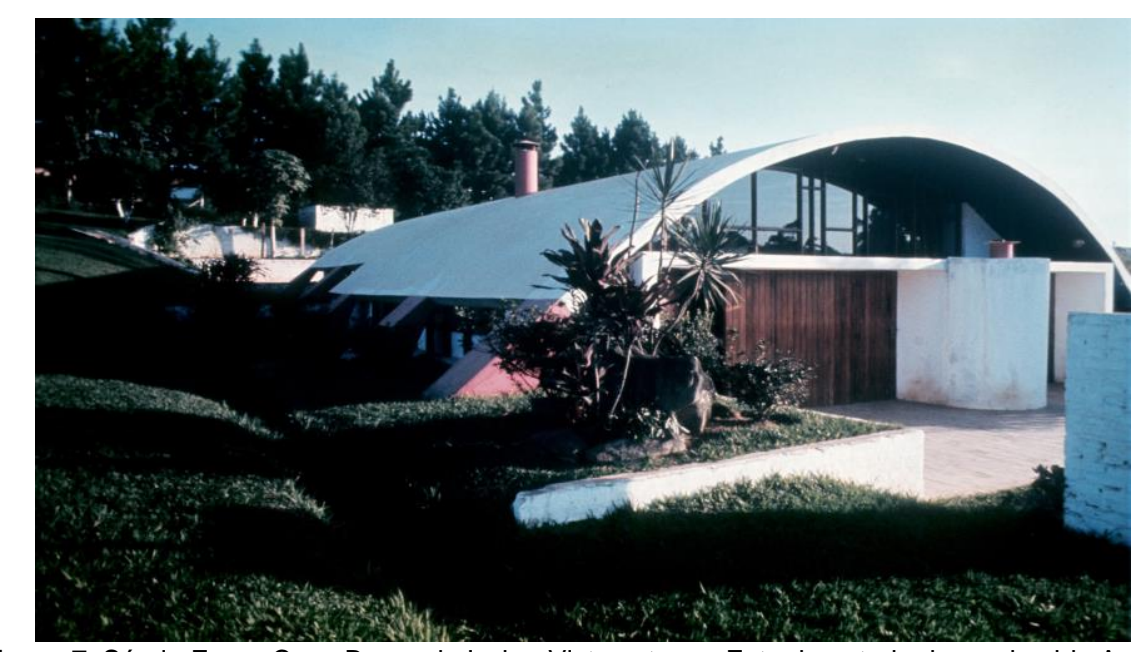

Figura 7. Sérgio Ferro, Casa Bernardo Issler. Vista externa. Foto de autoria desconhecida Acervo Rodrigo Lefèvre (Biblioteca FAU-USP).

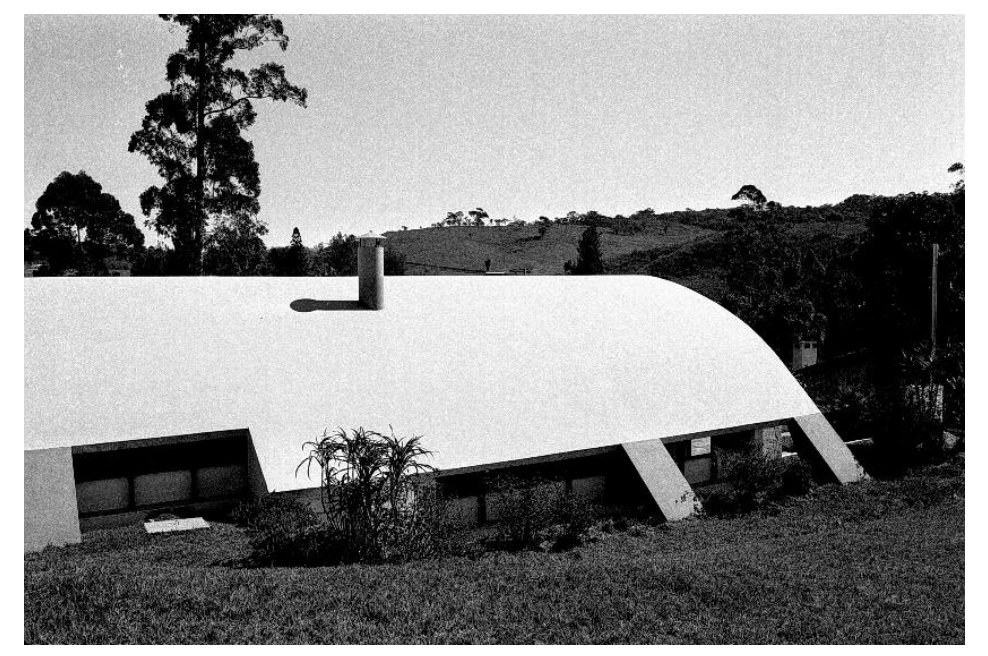

Figura 8. Sérgio Ferro, Casa Bernardo Issler. Vista externa. Foto de autoria desconhecida. Acervo Rodrigo Lefèvre (Biblioteca FAU-USP) 


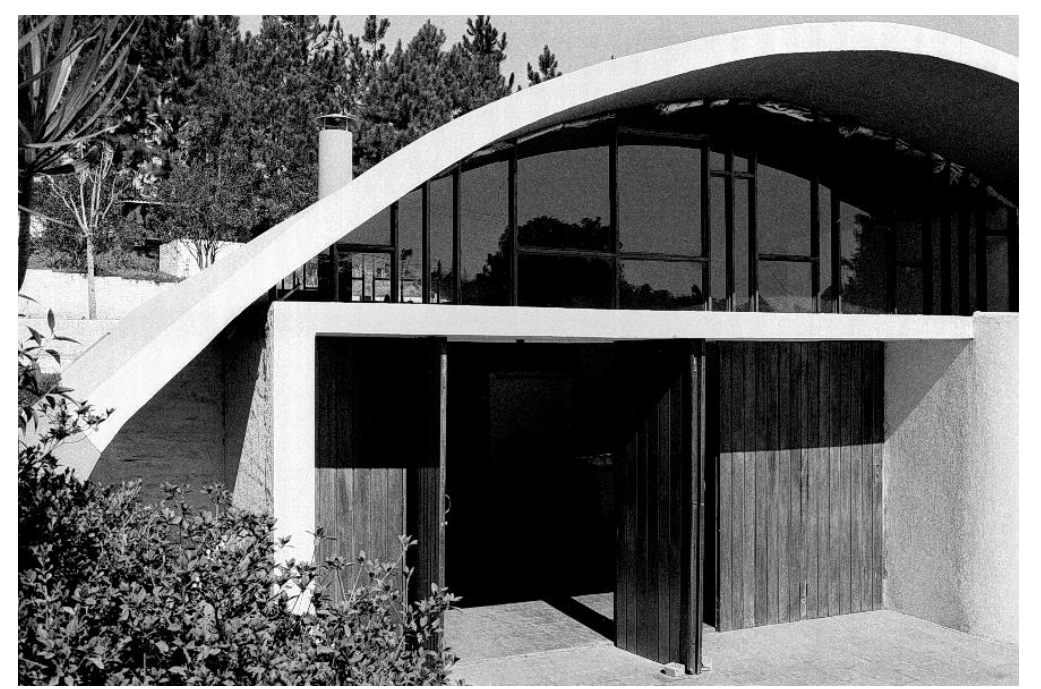

Figura 9. Sérgio Ferro, Casa Bernardo Issler. Vista externa. Foto de autoria desconhecida. Acervo Rodrigo Lefèvre (Biblioteca FAU-USP).

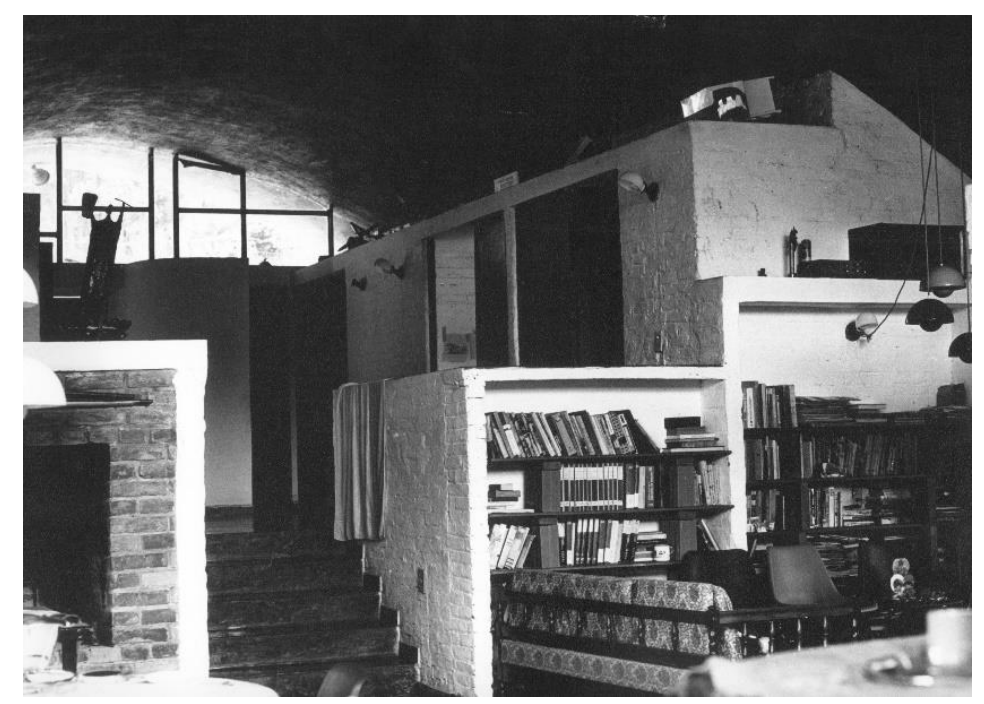

Figura 10. Sérgio Ferro, Casa Bernardo Issler. Vista interna. Foto de autoria desconhecida. Acervo Rodrigo Lefèvre (Biblioteca FAU-USP). 